\title{
Efficacy of physical therapy for the treatment of lateral epicondylitis: a meta-analysis
}

\author{
Christoph Weber ${ }^{1,2^{*}}$, Veronika Thai ${ }^{3}$, Katrin Neuheuser ${ }^{1,2}$, Katharina Groover ${ }^{1,2}$ and Oliver Christ $^{4}$
}

\begin{abstract}
Background: Physical therapy for the treatment of lateral epicondylitis (LE) often comprises movement therapies, extracorporeal shockwave therapy (ECSWT), low level laser therapy (LLLT), low frequency electrical stimulation or pulsed electromagnetic fields. Still, only ECSWT and LLLT have been meta-analytically researched.

Methods: PUBMED, EMBASE and Cochrane database were systematically searched for randomized controlled trials (RCTs). Methodological quality of each study was rated with an adapted version of the Scottish Intercollegiate Guidelines Network (SIGN) checklist. Pain reduction (the difference between treatment and control groups at the end of trials) and pain relief (the change in pain from baseline to the end of trials) were calculated with mean differences (MD) and $95 \%$-Confidence intervals (95\% Cl).

Results: One thousand one hundred thirty eight studies were identified. One thousand seventy of those did not meet inclusion criteria. After full articles were retrieved 16 studies met inclusion criteria and 12 studies reported comparable outcome variables. Analyses were conducted for overall pain relief, pain relief during maximum handgrip strength tests, and maximum handgrip strength. There were not enough studies to conduct an analysis of physical function or other outcome variables.

Conclusions: Differences between treatment and control groups were larger than differences between treatments. Control group gains were 50 to $66 \%$ as high as treatment group gains. Still, only treatment groups with their combination of therapy specific and non-therapy specific factors reliably met criteria for clinical relevance. Results are discussed with respect to stability and their potential meaning for the use of non-therapy specific agents to optimize patients' gain.
\end{abstract}

\section{Background}

Lateral epicondylitis (LE) is a painful musculoskeletal condition caused by overuse. The injury of the common extensor tendon originating from the lateral epicondyle is better known as tennis elbow. Both names are misleading though, since it is neither an inflammatory condition, nor does it only occur in tennis players. Other sports and jobs involving highly repetitive movements are strong contributors to the overuse-injury. It mostly affects people 40 years and older. Some studies indicate that men and women are equally affected [1], others report a higher percentage of affected women $[1,2]$. The

\footnotetext{
* Correspondence: weber@diempuberater.de

'Department of Psychology, TU Darmstadt, Alexanderstrasse 10, 64287

Darmstadt, Germany

2DMB Die MPU Berater GmbH, Bad Nauheimerstrasse 4, 64289 Darmstadt, Germany

Full list of author information is available at the end of the article
}

general prevalence rate ranges from 1 to $3 \%$ per year [2]. The National Guidelines Clearinghouse [3] recommends to first inform patients about the condition and to instruct them further to avoid aggravation [3]. The first pharmacological approach is to prescribe nonsteroidal anti-inflammatory drugs (NSAIDs). Also injection therapies for lateral epicondylitis are suggested. In a systematic review [4] the effects of prolotherapy, polidocanol, whole blood and platelet-rich plasma on lateral epicondylitis were measured. Strong pilot-level evidence was found but all studies were limited by small sample size. Newer studies showed small to none effects of injection therapies on pain and disability $[5,6]$. In general, treatments like splinting, stretching and strengthening exercises, soft tissue mobilisation and acupuncture are recommended [3].

Research on physical treatments for LE has not yet proven superiority of one specific approach. A meta- 
analysis by the Cochrane Collaboration [2] found little to no superiority of shock wave therapy over placebo and Bjordal et al. [7] found only short term effects of low level laser therapy (LLLT) over placebo. Both metaanalyses focused on one form of physical treatment.

The aim of this study was to meta-analyse the empirical evidence for physical treatments for LE and give practitioners an estimate of what benefits patients might expect from various treatments, both based on treatment specific and non-specific agents. Outcome differences between baseline and end-of-treatment were calculated for treatment and control groups as well as differences between treatment and control groups at end-of-treatment. Heterogeneity is discussed for each of these analyses.

\section{Methods}

\section{Searching}

We searched PUBMED, EMBASE and the Cochrane Database until April 2012 using medical subject headings related to epicondylitis when possible. The Search Key included the following key words: tendinoses, tendinosis, tendinitides, tendinitis, tendonitides, tendonitis, tendinopathy, epicondylalgia, epicondylitides, epicondylitis, tennis elbow. Further we hand-searched references of systematic reviews until April 2012 for additional studies. To identify grey literature we searched clinicaltrials.gov for registered RCTs on physical therapy for LE patients. Limits were set to randomized controlled trials with adults (18 years and older) and language restrictions were set to languages spoken by the authors (i.e., English and German).

\section{Selection}

Studies were eligible if they investigated a physical therapy intervention in comparison to a waiting-list control group, treatment as usual control group or sham-control group. If a study investigated a combination of therapy modalities (e.g., extra corporeal shockwave therapy in combination with manual therapy) the control group would have to match one of the therapy modalities (e.g., only extra corporeal shock wave therapy or only manual therapy). Orthoses, acupuncture, massage regimens, surgery, pharmacological treatments and psychotherapy were not included into the meta-analysis. Patients had to be diagnosed with LE. All outcomes were considered for inclusion as long as at least three studies used the same outcome measurement. Studies had to report mean, standard deviation and number of participants at baseline and at the end of treatment.

Study design was limited to RCTs, and each group under investigation had to consist of 10 or more patients.

\section{Validity assessment}

Four raters in groups of two independently rated the included studies, using an adapted form of the SIGN
Checklist for RCTs. The checklist consisted of eight items evaluating the key question, randomization procedure, blinding, comparability of treatment and control groups with respect to baseline measurements, study procedure and additional therapies, validity of outcome measurements, dropout rates and the use of intention-totreat analysis. The rating was conducted in three steps. Differences in step one were resolved by exchanging citations between raters, followed by re-rating. Differences in step 2 were resolved by discussion. Inter-rater reliability was calculated by Cohen's $\mathrm{k}$ for each rating step and with eight items per study.

Items were assessed either as "well", "poor" or "not addressed"/"not reported". If randomization (Item 1.2) was rated as "not addressed" or "not reported", the study was excluded for not meeting RCT criteria. Studies in which all aspects were rated as "well", were classified as Level of Evidence (LoE) "++" for "good, very low risk of bias". If four or more aspects were rated as"poor" or "not addressed" the study was classified as LoE "- "for "poor, high risk of bias". Studies were also rated as LoE "poor, high risk of bias" if the comparability of groups with respect to study procedures was deemed compromised (Item 1.6). Similar, if neither intention-to-treat analysis was performed (Item 1.9) nor adequate blinding measures were employed (Item 1.4), the study was rated as LoE "poor, high risk of bias". All other studies were classified as LoE "+" "fair, low risk of bias".

\section{Data extraction}

The following data were extracted from each study: means and standard deviations of pain intensity, Disabilities of the Arm, Shoulder and Hand (DASH) function score, maximum handgrip strength in $\mathrm{kg}$, pain during maximum handgrip strength test, group size, type of treatment, control group intervention, treatment duration, treatment frequency, assessment schedules and time since diagnosis of LE. All pain scales were transformed linearly to a $0-100$ point scale. For scales from 0 to y: transformed $M E A N=M E A N \times(100 \div y)$. For scales from 1 to $\mathrm{y}$ : transformed MEAN $=(M E A N-1) \times(100 \div$ $(y-1))$. Standard deviations were transformed as follows: transformed $S D=S D \times(100 \div y)$ for scales from 0 to $\mathrm{y}$; transformed $S D=S D \times(100 \div(y-1))$ for scales from 1 to y. All hand grip strength scales were transformed into $\mathrm{kg}$. If no minimum and maximum duration of illness was reported, mean plus/minus two standard deviations was used to estimate the interval which should include about $95 \%$ of participants.

Data were extracted by two independent investigators, differences were solved by discussion. Since there was only one LLLT study and one ECSWT study which reported DASH scores, no further analysis was conducted for physical function. 


\section{Quantitative data synthesis}

Effect sizes were calculated by mean differences (MD). Given standard errors were transformed into standard deviations. No authors were contacted for missing data. Statistical heterogeneity was assessed by $\mathrm{I}^{2}=[(\mathrm{Q}-\mathrm{df}) / \mathrm{Q}]$ $\times 100 \%$, where $\mathrm{Q}$ is the chi-squared statistic and $\mathrm{df}$ is its degrees of freedom. $\mathrm{I}^{2}$ describes the percentage of the effect estimates variability which can be attributed to heterogeneity. Since effect sizes of studies testing against waiting-list (WLC) or treatment as usual control groups tend to be higher than those testing against sham-control or active control groups, studies were split into three subgroups; 1) waiting-list or treatment as usual control groups, 2) sham-control groups, and 3) studies which compared a combination of two treatments to the single application of one of those treatments. Publication bias was assessed by Egger's regression intercept using Comprehensive-Meta-Analysis Software (CMA Software).

\section{Statistical methods and outcomes}

Results are reported as MD [95\% CI] $\left(\mathrm{I}^{2}\right)$. Mean Difference (95\% Confidence Interval] (Heterogeneity); with (s.) showing statistical significance and (n.s.) showing non significance. Two types of MDs are being reported. MDs between treatment and control groups are indicated as "difference between treatment and control groups". MDs between baseline and end-of-treatment are indicated as "difference from baseline".

\section{Results}

\section{Trial flow}

Figure 1 shows a flow diagram of the selection processes. One thousand one hundred thirty eight studies were identified. One thousand seventy of those did not meet inclusion criteria. The remaining 68 were retrieved as full text articles and checked for inclusion and exclusion criteria once again. Seventeen studies met all criteria and were considered for quantitative synthesis. Twelve of those reported comparable outcome measures. Since only two studies $[8,9]$ investigated a combination of therapies, each reporting different outcome measurements, neither study was included in the meta-analyses. Only one study used a WLC design and therefore was excluded [10]. The remaining nine studies were included in the analysis; three investigated LLLT, four ECSWT, one low frequency electrical stimulation and one pulsed electromagnetic field therapy (PEMF). There were not enough comparable studies to evaluate any other treatment (Table 1).

\section{Study characteristics}

\section{Quantitative data synthesis}

Sixteen studies were included in the rating procedure [8-23]. One study was rated as LoE “++" [11], 7 studies were rated as LoE " + " $[10,15,17-21]$ and 8 studies were rated as LoE “-“ $[8,9,12-14,16,22,23]$. Cohen's $\mathrm{K}$ was calculated to assess inter-rater reliability for each rating step $\kappa_{\text {step } 1}=0.46 ; \kappa_{\text {step } 2}=0.83 ; \kappa_{\text {step } 3}=1$.

In the end, five analyses could be conducted; the first on the effect of physical therapy (ECSWT, LLLT, low frequency electrical stimulation and PEMF) on pain; the second on the effect of extracorporeal shockwave therapy (ECSWT) on pain; the third on the effect of nonECSWT treatments (LLLT, low frequency electrical stimulation and PEMF) on pain; the fourth on the effect of LLLT on pain during maximum handgrip strength tests, and the fifth on the effect of physical therapy treatments (LLLT and ECSWT) on maximum handgrip strength. The analysis on the effect of physical therapy on physical functioning was not conducted due to the heterogeneity of measurement instruments. Two studies reported DASH (sports/music, work) scores, one DASH function, one an adapted patient specific function scale, and one the upper extremeties function scale. The authors considered these scales too heterogeneous to combine.

Review Manager Software (RevMan 5) by the Cochrane Collaboration was used to conduct the five analyses.

All reported pain outcomes were transformed to a 0100 scale and all grip strength outcomes to $\mathrm{kg}$.

\section{Overall pain ECSWT, LLLT, low frequency electrical stimulation and PEMF}

Outcomes used were pain during the last $24 \mathrm{~h}$, pain during activity, pain during Thomsen Test, pain during day and night, and pain at isometric testing.

Combined Pain relief in treatment groups (difference from baseline) was -32.87 [95 \% CI $=-37.04,-28.70]\left(\mathrm{I}^{2}=\right.$ $18 \%$ ) (s.) (Fig. 2), with only one study [24] reporting pain relief below 25. Combined Sham-control groups reported -21.07 [95 \% CI = -27.87, -14.27] $\left(\mathrm{I}^{2}=65 \%\right)$ (s.) (Fig. 3) units of pain relief (difference from baseline). Comparing pain intensity outcomes of treatment and control groups at the end of treatment resulted in -7.50 [95\% CI = $-14.94,-0.07$ ] ( $\left.\mathrm{I}^{2}=78 \%\right)$ (s.) (Additional file 1) units difference in pain reduction.

\section{Overall pain ECSWT}

If only ECSWT studies were analysed combined treatment groups reported -34.79 [95 \% CI $=-39.98,-29.60]$ $\left(\mathrm{I}^{2}=24 \%\right)$ (s.) (Fig. 4) units of pain relief (difference from baseline). Combined Control groups in ECSWT studies reported $-24.48[95 \% \mathrm{CI}=-32.65,-16.31]\left(\mathrm{I}^{2}=\right.$ $66 \%)$ (s.) (Fig. 5) units of pain relief (difference from baseline). Comparing pain intensity between ECSWT and control groups at the end of studies resulted in a statistically non significant pain reduction of -7.20 [95\% $\mathrm{CI}=-17.44,3.04] \quad\left(\mathrm{I}^{2}=82 \%\right) \quad$ (n.s.) (Additional file 2). Three of these four studies were of high methodological 


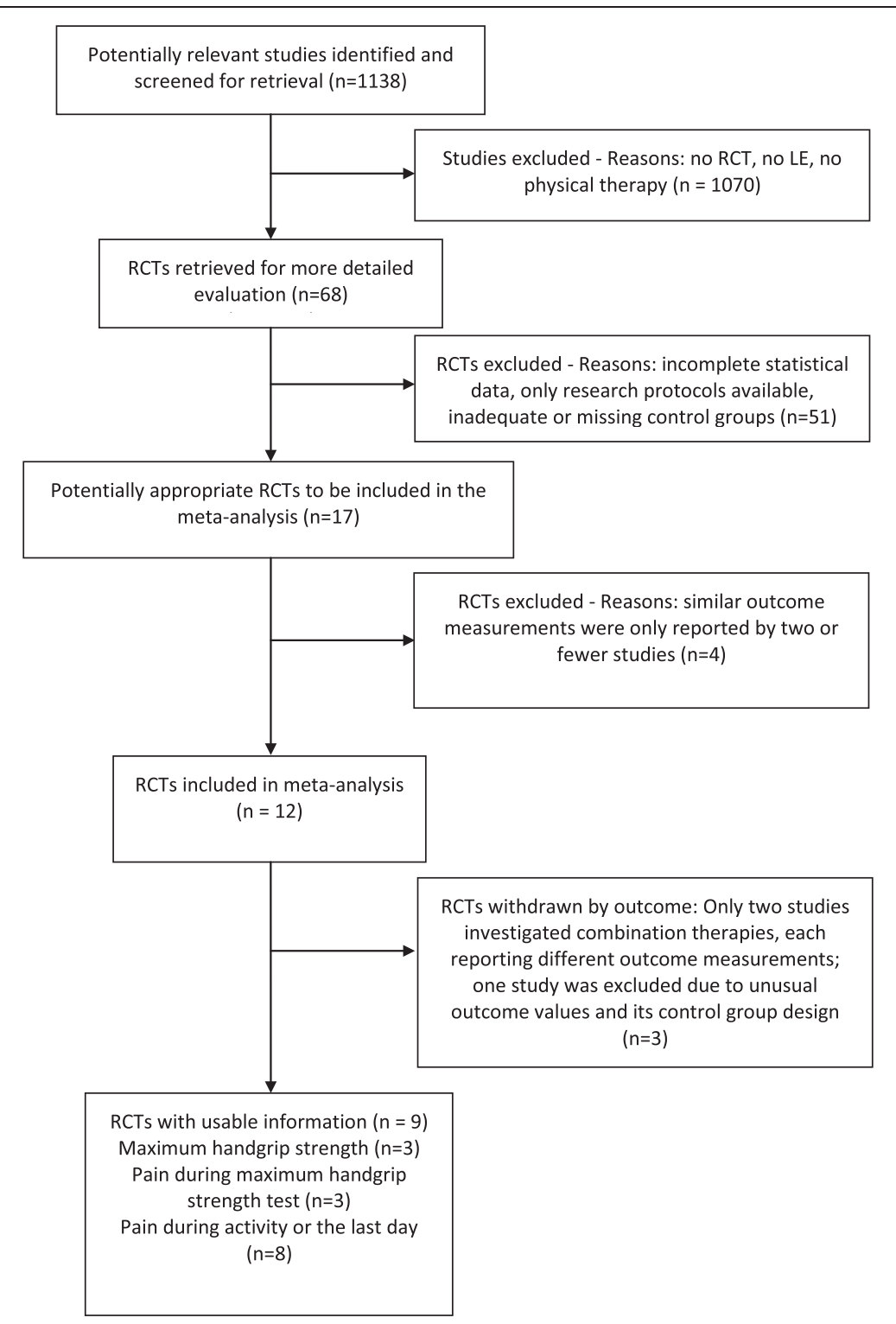

Fig. 1 Flow diagram of the article selection process

quality reporting a combined pain reduction of 5.13 [95 \% $C I=-16.71,6.46] \quad\left(I^{2}=82 \%\right) \quad$ (n.s.) (difference between treatment and control groups).

Only two studies remained for a LLLT sub-group analysis. Thus, no effect size calculations were conducted.

\section{Overall pain LLLT, low frequency electrical stimulation and PEMF}

Two LLLT studies, one low frequency electrical stimulation study and one PEMF study reported sufficient data to be analysed. Combined Non-ECSWT treatment groups gained $-29.35[95 \% \mathrm{CI}=-35.84,-22.86]\left(\mathrm{I}^{2}=0 \%\right)(\mathrm{s}$. $)$ (Fig. 6) units of pain relief (difference from baseline). The respective combined control groups gained -16.38 [95\%
$\mathrm{CI}=-27.08,-5.68]\left(\mathrm{I}^{2}=54 \%\right)$ (s.) (Fig. 7) (difference from baseline). Comparing treatment and control groups at the end of trials resulted in a pain reduction of -8.12 [95\% $\mathrm{CI}=-20.83,4.60]\left(\mathrm{I}^{2}=71 \%\right)$ (n.s.) (Additional file 3$)$.

\section{Pain during maximum handgrip strength tests}

Three studies reported data on pain during maximum handgrip strength tests, all investigating LLLT. Combined treatment groups gained -19.16 [95 \% CI = $-25.20,-13.11]\left(\mathrm{I}^{2}=0 \%\right)$ (s.) (Additional file 4) units of pain relief (difference from baseline). Control groups gained $-2.58[95 \% \mathrm{CI}=-11.69,6.52]\left(\mathrm{I}^{2}=33 \%\right)$ (n.s.) (Additional file 5) units of pain relief (difference from baseline). Difference in pain intensity between treatment 
Table 1 Studies considered for inclusion

\begin{tabular}{|c|c|c|c|c|c|c|c|}
\hline Article & Author & Year & Reported outcomes & Treatment duration & Times of measurements & Symptom duration & Treatment \\
\hline [11] & Basford et al. & 2000 & $\begin{array}{l}\text { apain in last } 24 \mathrm{~h} \\
\text { maximal tenderness on palpation } \\
\text { amaximum grip strength } \\
\text { pinch strength } \\
\text { apain with grasp } \\
\text { pain with pinch }\end{array}$ & 3S/W for $4 \mathrm{Ws}$ & 2 Ws, 4 Ws, follow-up & $1-17 \mathrm{Ms}$ & LLLT vs placebo \\
\hline [12] & Bisset et al. & 2009 & reaction time & $8 \mathrm{~S}$ over $6 \mathrm{Ws}$ & $6,52 \mathrm{Ws}$ & 6-89 Ms & Physical therapy vs WLC \\
\hline [13] & Haake et al. & 2002 & side effects & 1S/W over? Ws & $?$ & $1-99 \mathrm{Ms}$ & ECSWT vs placebo \\
\hline [7] & Ho et al. & 2007 & $\begin{array}{l}\text { mechanical pain threshold } \\
{ }^{\mathrm{b}} \text { pain-free handgrip strength } \\
{ }^{\mathrm{b}} \text { maximum handgrip strength } \\
\text { pain during max grip }\end{array}$ & $10 \mathrm{~S}$ over $3 \mathrm{Ws}$ & 1, 2, 3 Ws, follow-up 3 Ws & 3-15 Ms & Microcurrent \& exercise vs exercise \\
\hline [14] & Lam et al. & 2007 & 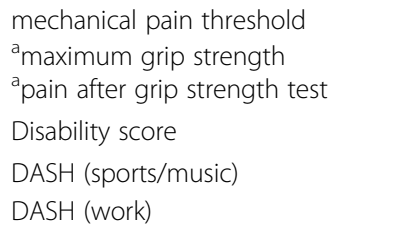 & $3 S / \mathrm{W}$ for $3 \mathrm{Ws}$ & $\begin{array}{l}\text { Session } 5,9 \& 3 \text { Ws } \\
\text { after completion }\end{array}$ & $1-9 \mathrm{Ms}$ & LLLT vs placebo \\
\hline [9] & Martinez-Silvestrini et al. & 2005 & $\begin{array}{l}\text { pain free grip strength } \\
\text { bVAS pain } \\
\text { PRFEQ } \\
{ }^{\text {b }} \text { dash function }\end{array}$ & Daily for 6 Ws & $6 \mathrm{Ws}$ & $3+\mathrm{Ms}$ & $\begin{array}{l}\text { Stretching vs stretching \& concentric vs } \\
\text { stretching \& eccentric strengthening }\end{array}$ \\
\hline [15] & Nourbakhsh et al. & 2008 & $\begin{array}{l}{ }^{c} \text { maximum grip strength } \\
\text { a pain intensity last } 24 \mathrm{~h} \\
\text { functional level (adapted patient } \\
\text { specific function scale) } \\
\text { limited activity due to pain }\end{array}$ & $6 \mathrm{~S}$ over $2-3 \mathrm{Ws}$ & Post treatment, follow-up & $6-60 \mathrm{Ms}$ & $\begin{array}{l}\text { Low frequency electrical stimulation } \\
\text { vs placebo }\end{array}$ \\
\hline [10] & Peterson et al. & 2011 & $\begin{array}{l}\text { pain MVC } \\
\text { pain MME } \\
{ }^{\text {}} \text { muscular strength } \\
\text { activity score } \\
\text { well-being } \\
\text { complaint score }\end{array}$ & $\begin{array}{l}\text { 1S/D exercise } \\
\text { regimen over } 3 \mathrm{Ms}\end{array}$ & $1,2,3 \mathrm{Ms}$ & $3+\mathrm{Ms}$ & Exercise vs WLC \\
\hline [16] & Pettrone et al. & 2005 & 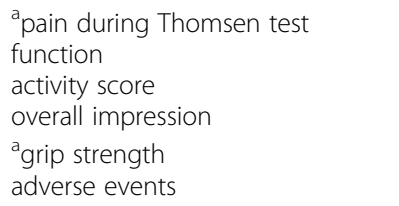 & 1S/W over $3 \mathrm{Ws}$ & $\begin{array}{l}1,4,8,12 \mathrm{Ws} ; 6,12 \mathrm{Ms} \\
\text { only reported at } 12 \mathrm{Ws}\end{array}$ & $6+\mathrm{Ms}$ & ECSWT vs placebo \\
\hline
\end{tabular}


Table 1 Studies considered for inclusion (Continued)

\begin{tabular}{|c|c|c|c|c|c|c|c|}
\hline [17] & Rompe et al. & 1996 & $\begin{array}{l}\text { night pain } \\
\text { resting pain } \\
\text { pressure pain } \\
\text { Thomsen test } \\
\text { finger extension } \\
\text { chair test } \\
\text { cgrip strength (Mucha and Wannske) }\end{array}$ & 1S/W over $3 \mathrm{Ws}$ & $\begin{array}{l}3,6,24 \text { Ws after } \\
\text { last application }\end{array}$ & $12+\mathrm{Ms}$ & ECSWT vs sham \\
\hline \multirow[t]{2}{*}{ [18] } & Rompe et al. & 2001 & pressure pain & 1S/W over 3 Ws & $12 \mathrm{Ws}, 12 \mathrm{Ms}$ & $12-208 \mathrm{Ms}$ & ECSWT vs ECSWT + manual therapy \\
\hline & & & $\begin{array}{l}\text { Thomsen test resisted finger extension } \\
\text { chair test }\end{array}$ & & & & \\
\hline \multirow[t]{2}{*}{ [19] } & Rompe et al. & 2004 & ${ }^{a}$ pain during Thomsen test & 1S/W over $3 \mathrm{Ws}$ & $3,12 \mathrm{Ms}$ & $12+\mathrm{Ms}$ & ECSWT vs sham \\
\hline & & & $\begin{array}{l}\text { Roles and Maudsley score } \\
\text { upper extremity function scale } \\
\text { bdynanometer test }\end{array}$ & & & & \\
\hline [20] & Speed et al. & 2002 & $\begin{array}{l}{ }^{a} \text { Pain (day and night) } \\
\text { night pain } \\
50 \% \text { improvement from baseline }\end{array}$ & 1S/M for $3 \mathrm{Ms}$ & $1 ; 2 ; 3 \mathrm{Ms}$ & $3-42 \mathrm{Ms}$ & ECSWT vs placebo \\
\hline \multirow[t]{2}{*}{ [21] } & Staples et al. & 2008 & $\begin{array}{l}\text { aoverall pain index } \\
\text { function index }(0-100 \text { VAS) } \\
\text { pain-free function index } \\
\text { dash function }(0-100) \\
\text { dash sport }(0-100) \\
\text { dash work (0-100) } \\
\text { pain free grip ratio }\end{array}$ & 1S/W over $3 \mathrm{Ws}$ & $6 \mathrm{Ws} ; 3,6 \mathrm{Ms}$ & $6-520$ Ws & ECSWT vs sham \\
\hline & & & $\begin{array}{l}\text { bmax grip strength } \\
\text { SF-36 } \\
\text { role limitation physical } \\
\text { bodily pain } \\
\text { general health } \\
\text { vitality } \\
\text { social function } \\
\text { role limitation emotional } \\
\text { mental health } \\
\text { health transition } \\
\text { problem elicitation technique } \\
\text { PET global health }\end{array}$ & & & & \\
\hline \multirow[t]{3}{*}{ [22] } & Sterigioulas et al. & 2007 & $\begin{array}{l}\text { pain at rest } \\
\text { pain at palpation }\end{array}$ & $\begin{array}{l}\text { 2S/W over first } 4 \mathrm{Ws} \\
1 \mathrm{~S} / \mathrm{W} \text { over second } 4 \mathrm{Ws}\end{array}$ & $\begin{array}{l}8 \mathrm{Ws}, 8 \mathrm{Ws} \text { after } \\
\text { end of treatment }\end{array}$ & $5 \mathrm{Ws}-12$ Ys & LLLT \& exercise vs placebo and exercise \\
\hline & & & $\begin{array}{l}{ }^{a} \text { pain on isometric testing } \\
\text { pain during middle finger test }\end{array}$ & & & & \\
\hline & & & apain during grip strength test & & & & \\
\hline [47] & Öken et al. & 2008 & $\begin{array}{l}\text { Grip strength } \\
\text { Pain severety }\end{array}$ & 5S/W over two weeks & $\begin{array}{l}2 \mathrm{Ws}, 4 \mathrm{Ws} \text { after } \\
\text { end of treatment }\end{array}$ & $1-24 \mathrm{Ms}$ & $\begin{array}{l}\text { Ultrasound \& hot pack vs LLLT \& hot } \\
\text { pack vs brace control group }\end{array}$ \\
\hline
\end{tabular}


Table 1 Studies considered for inclusion (Continued)

\begin{tabular}{|c|c|c|c|c|c|c|c|}
\hline [23] & Uzunca et al. & 2007 & $\begin{array}{l}\text { resting pain } \\
\text { activity pain } \\
\text { night pain } \\
\text { pain during resisted wrist } \\
\text { dorsiflexion pain during resisted forearm } \\
\text { supination } \\
\text { algometric pain threshold }\end{array}$ & $5 \mathrm{~S} / \mathrm{W}$ over $3 \mathrm{Ws}$ & $3 \mathrm{Ws}, 3 \mathrm{Ms}$ & $1-11 \mathrm{Ms}$ & $\begin{array}{l}\text { Pulsed electromagnetic field (PEMF) } \\
\text { vs sham PEMF }\end{array}$ \\
\hline
\end{tabular}

$W$ week, $M$ month, $S$ Session

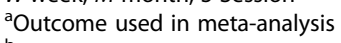

${ }^{\mathrm{b}} \mathrm{Not}$ included due to control group design

${ }^{\mathrm{c}}$ Not included since the authors could not assuredly establish a method to transform data into $\mathrm{kg}$ 


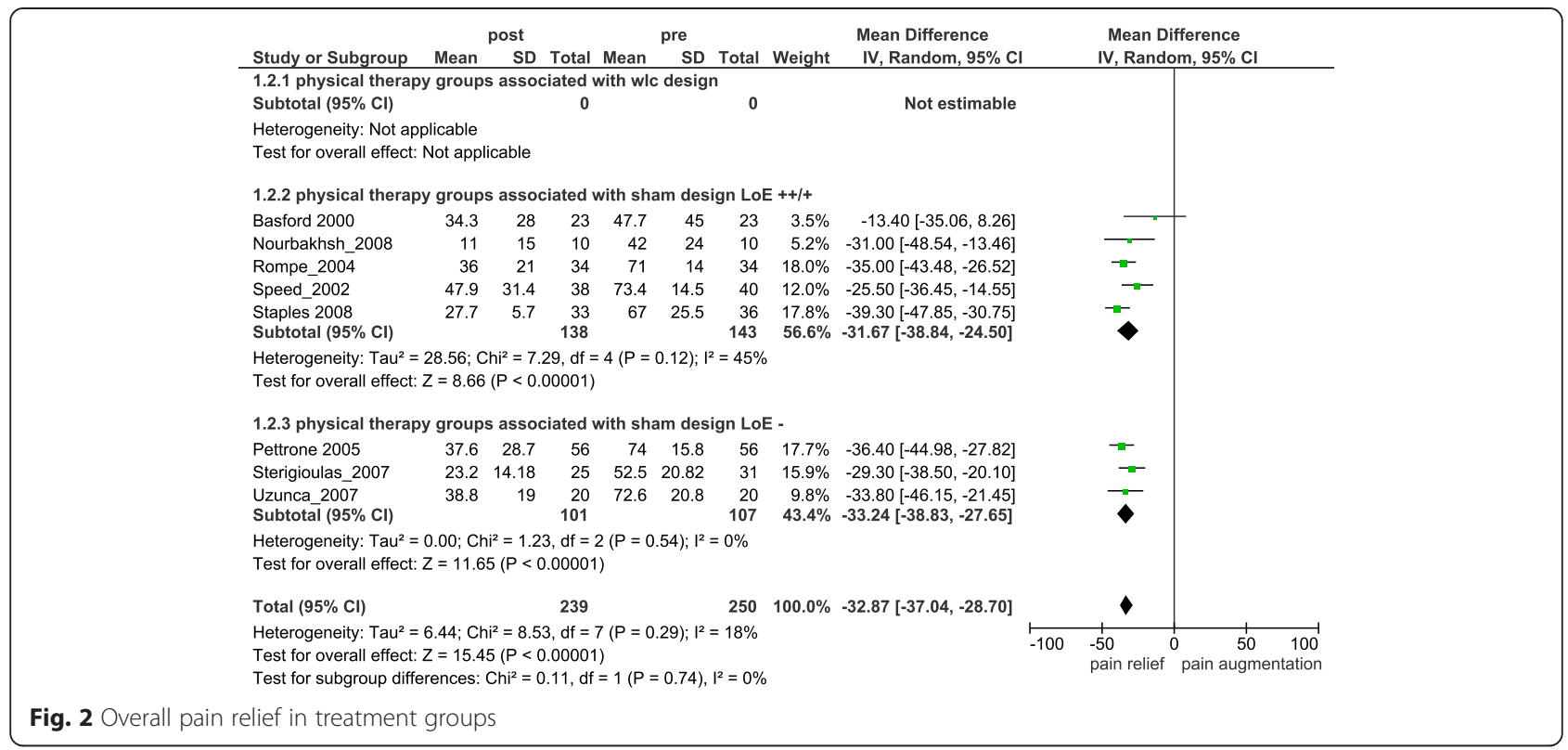

and control groups at end of treatment was -7.92 [95\% $\mathrm{CI}=-22.65,6.81]\left(\mathrm{I}^{2}=79 \%\right)$ (n.s.) (Additional file 6).

\section{Physical function}

Only two studies remained for a physical function analysis. Thus, no effect size calculations were conducted.

\section{Maximum handgrip strength}

Three studies reported maximum grip strength, two investigating LLLT and one investigating ECSWT. Treatment groups had mean maximum handgrip strength gain of $6.47 \mathrm{~kg}$ [95 \% CI = 3.68, 9.26] $\left(\mathrm{I}^{2}=0 \%\right)$ (s.) (Additional file 7) (difference from baseline). Control groups had a mean maximum handgrip strength gain of $2.81 \mathrm{~kg}$ [95\% $\mathrm{CI}=-1.25,6.88]\left(\mathrm{I}^{2}=0 \%\right)$ (n.s.) (Additional file 8) (difference from baseline). Comparison between treatment and control groups at the end of studies showed a MD of $3.47 \mathrm{~kg}$ [95 \% CI =0.17, 6.76] $\left(\mathrm{I}^{2}=0 \%\right)$ (s.) (Additional file 9) in favour of treatment groups. Since there was only one ECSWT and two LLLT studies, no sub-group analyses were conducted.

\section{Risk of bias across studies}

Egger's regression intercept showed no significant small study effects for overall pain reduction $\mathrm{t}(6)=1.83$, $\mathrm{p}=0.25$; overall pain reduction in ECSWT $\mathrm{t}(2)=0.24 ; \mathrm{p}=0.83$; 


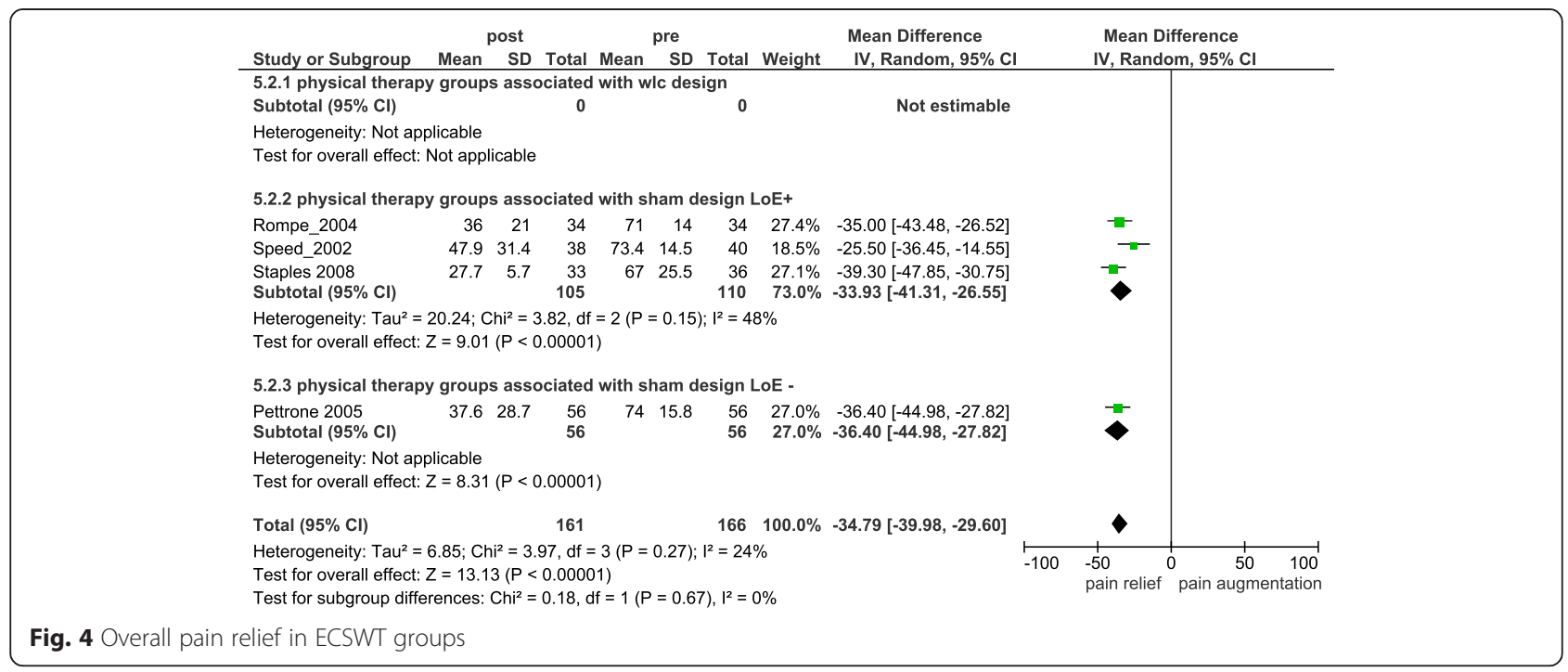

overall pain reduction in non-ECSWT $\mathrm{t}(2)=1.32 ; \mathrm{p}=0.32$; pain reduction during maximum handgrip strength tests $\mathrm{t}(1)=2.28 ; \mathrm{p}=0,26$ and maximum handgrip strength $\mathrm{t}(1)=$ 0,$47 ; \mathrm{p}=0,72$.

\section{Discussion}

\section{Summary of key findings}

Two other meta-analyses have analyzed the effects of either ECSWT [2] or LLLT [7] on LE. This meta-analysis differs from its predecessors in two major aspects. One, it tried to investigate a wide variety of physical treatments, both in changes from baseline and differences between treatment and control groups at the end of treatment. Two, only completely published data was used and no authors were contacted for further data.

All in all, treatment groups had between 29 and 35 units and control groups between 16 and 25 units of pain relief. Differences between treatment and control groups at the end of treatment were generally low, ranging only from 7 to 9 units on a $0-100$ scale. Of five comparisons between treatment and placebo groups only one, the combined analysis of ECSWT and nonECSWT studies, showed statistically significant results. This finding should be interpreted with utmost reluctance, since neither ECSWT studies alone, nor NonECSWT studies alone showed statistically significant differences between treatment and placebo groups. With rather large pain relief scores in both, treatment and placebo groups, and only small differences between treatment and placebo groups it can be concluded that a large portion of therapy effects are attributable to contextual factors.

These findings resemble those of Buchbinder et al. [2] who found that ECSWT is no more effective than placebo. For pain at rest they report a MD (pain out of 100) of $-9.42[95 \% \mathrm{CI}=-20.7,1.86]$.

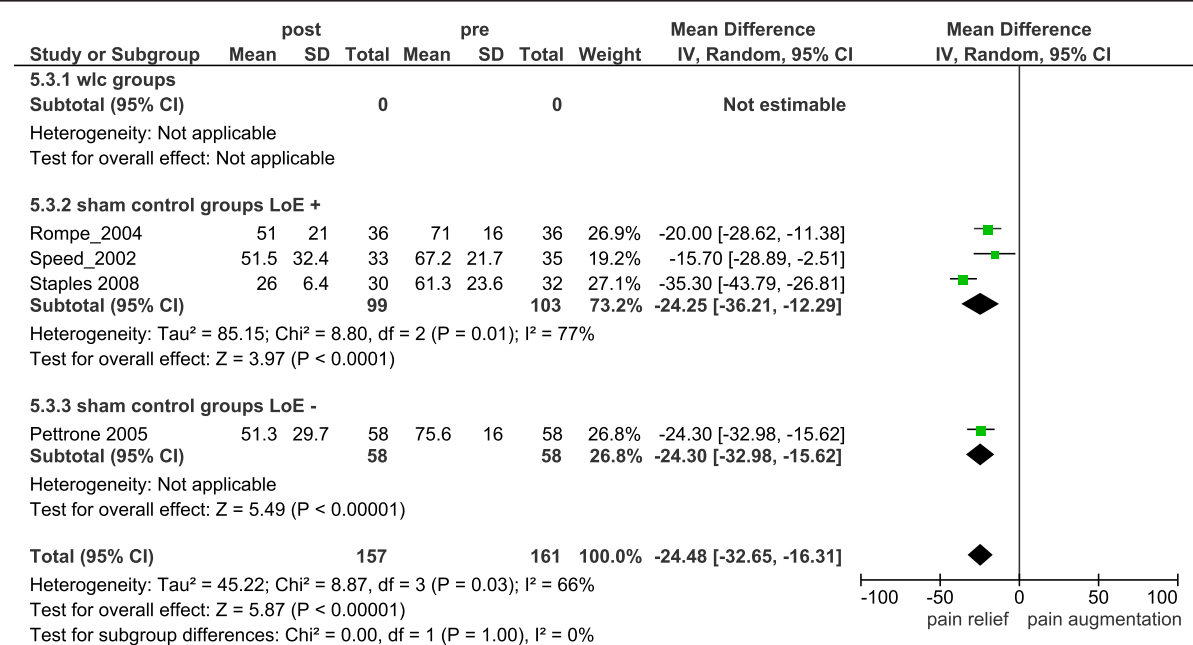

Fig. 5 Overall pain relief in sham-ECSWT groups 


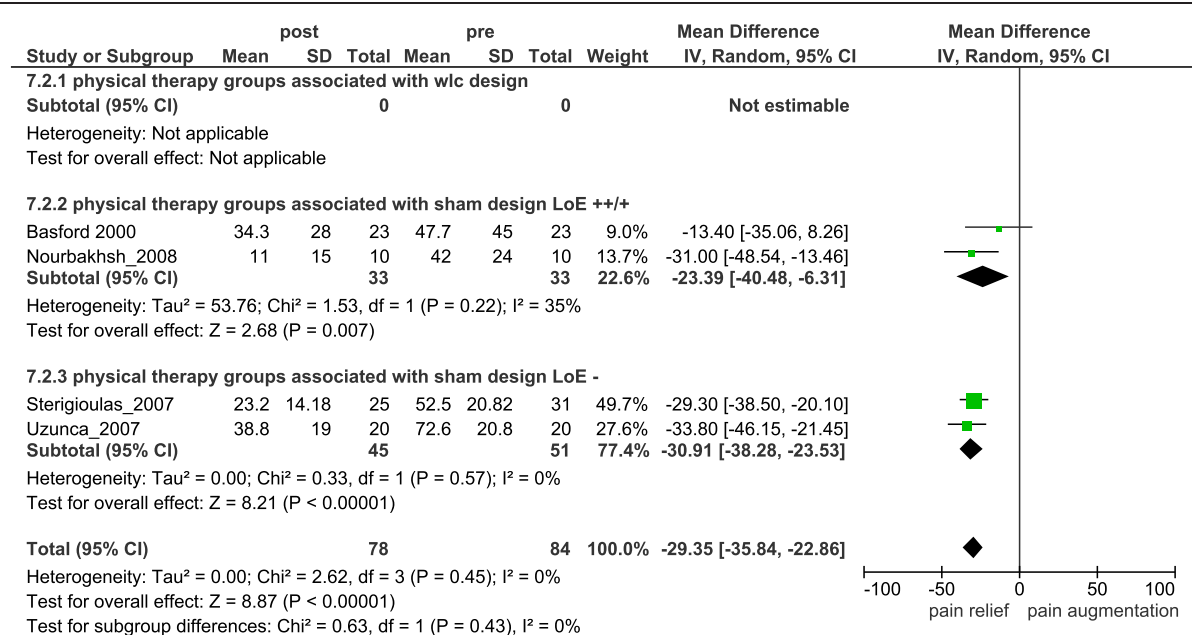

Fig. 6 Overall pain relief in Non-ECSWT treatment groups

Bjordal et al. [7] analyzed 7 studies of LLLT for the treatment of LE. In contrast to Bjordal et al. [7] this meta-analysis identified only 2 LLLT studies which both, met inclusion criteria and published sufficient data for meta-analysis. This meta-analysis did not include six studies which were included in Buchbinder et al. [2]. Five studies were excluded due to not reported standard deviations $[9,13,25-27]$, one was not included since the underlying data is not published [28-35].

Since there were no authors contacted for this metaanalysis a lower number of studies was to be expected. Due to the small number of studies this meta-analysis offers no interpretation concerning the effectiveness of LLLT in the treatment for LE. Bjordal et al. [7] concluded that LLLT was safe and effective and that it acted in a dose dependent manner.

Pain relief during maximum handgrip strength tests was generally lower than overall pain relief. Treatment groups had a mean pain relief of 19 units on a $0-100$ scale and control groups had about 3 units. Still, differences in comparisons between those groups at the end of treatment resulted in only 8 units of pain reduction on a $0-100$ scale, which might partly come from a shift of weights in this analysis. Treatment groups' maximum handgrip strength improved by $6 \mathrm{~kg}$ while control groups improved by $3 \mathrm{~kg}$. The mean difference between treatment and control groups at the end of treatment was $3 \mathrm{~kg}$.

Both, Buchbinder et al. [2] and Bjordal et al. [7] explicitly state the need for further research. Buchbinder et al. [2] especially criticize "a lack of uniformity in both the timing of follow up and the outcomes that were measured". This meta-analysis found the same methodological heterogeneity. As can be seen in Table 1, treatment duration, treatment intensity, symptom duration, times of measurement and reported outcomes vary largely between studies.

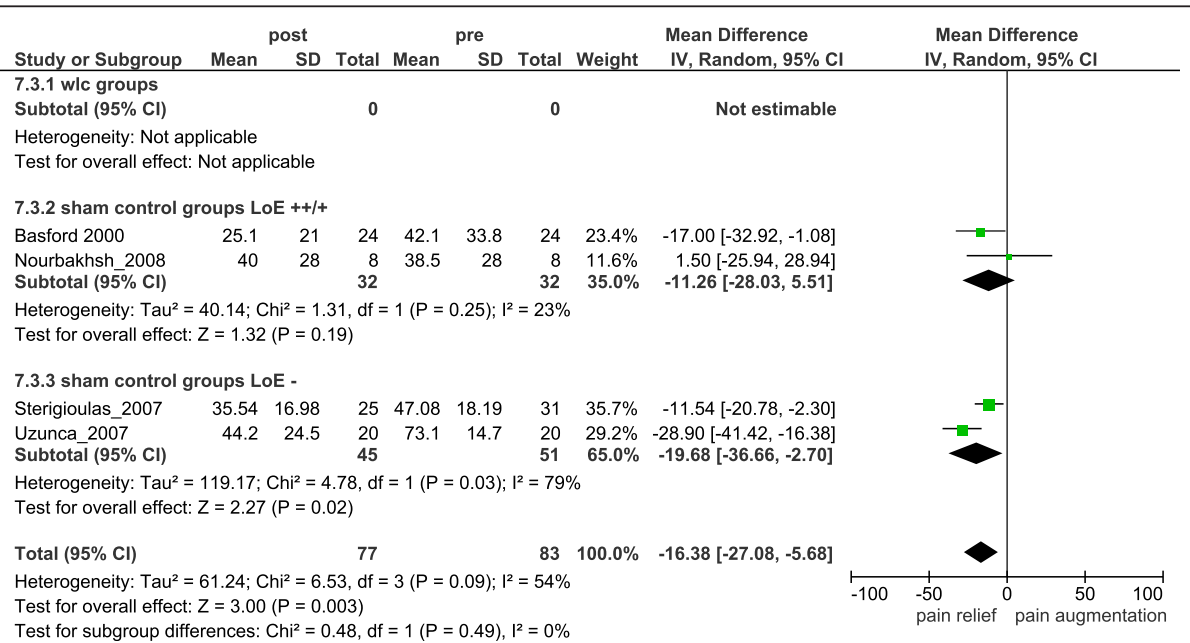

Fig. 7 Overall pain relief in Non-ECSWT sham-groups 


\section{Conclusions}

Treatment groups showed more homogeneous outcomes than we expected from the differing treatment modalities $\left(\mathrm{I}^{2}=18 \%\right)$. The mean pain relief amounted to 32.9 units in treatment groups and to 21.1 units in control groups. The difference between treatment and control groups in mean pain relief amounted to 11.8 units on a $0-100$ scale. Thus, control groups gained about $2 / 3$ of treatment groups' overall pain relief. Differences between ECSWT (34.8 units of pain relief) and non-ECSWT studies (30.4 units of pain relief) only amounted to 4 units. This means that the difference between treatments seems to be lower than the difference between treatments and their respective control groups. If further studies produced similar results this might indicate that the decision which physical therapy treatment to use (ECSWT, LLLTlow frequency electrical stimulation or PEMF) might not be as important as maximizing nontreatment specific effects.

During physical therapy patients do not only benefit from the treatment itself, e.g., the pharmacological effect of a drug or the physical effect of a laser therapy, but also from non-treatment specific agents, the so called sham-effects, placebo-effects or contextual effects [36]. Patients' pain relief thus results from a combination of treatment specific agents and non-treatment specific agents. Important non-specific agents can be e.g., spontaneous remission, expectancy, motivation, conditioning and other psychosocial agents [36].

With the combination of contextual and therapyspecific factors about $95 \%$ of patients in treatment groups gained between 28 and 38 units of pain relief on a $0-100$ scale, compared to 14 to 28 units in control groups and by contextual effects, only.

The difference between treatment and placebo groups at the end of treatment was rather low. Still, only treatment groups with their combination of specific and unspecific agents managed to rather reliably reach clinically important pain relief of more than 22 units on a 0 100 scale [37]. Patients in sham groups with their purely unspecific agents only gained clinically relevant pain relief in less than $50 \%$ of cases.

\section{Limitations}

Altogether, for overall pain 473 patients were analyzed, for pain during maximum handgrip strength test 136 patients and for maximum handgrip strength 193 patients. These numbers are much lower than those reported of patient collectives, studied e.g., in pharmaceutical trials for WHO I (non-opioid analgesics) or WHO II (weak opioids) analgesics which regularly evaluate over 100 patients per group per study [33, 38-46]. In the overall pain analysis 318 of 473 patients were treated with ECSWT, 97 with LLLT, 18 with low frequency electrical stimulation, and 40 with pulsed electromagnetic field therapy. Thus, ECSWT results might be relatively stable while non-ECSWT results might change, even with only a few new studies.

Patients varied largely in their duration of symptoms, making it impossible to differentiate between studies with only acute or only chronic LE patients. Minimum symptom duration varied between 4 weeks and 12 months, maximum duration between 9 months and 17 years, with several studies not reporting a cut-off point at all.

While some studies investigated treatment effects as early as after the last treatment session, some studies let several weeks or months pass before measuring post treatment effects. Even though follow-up investigations help understand the long-term effects of a therapy, a prolonged period of time between the end of a treatment and the assessment of its effectiveness may distort results. Especially changes in patients' activities or therapy regimen, as well as social context may influence trial results.

Another distorting factor in this meta-analysis was the rather large difference in treatment durations and sessions per week. Studies went on over time periods of at least three weeks to a maximum of three months. During this time treatments were applied a minimum of once per month to a maximum of five sessions per week. Thus, study effects were achieved with largely differing efforts.

Still overall pain relief $\left(\mathrm{I}^{2}=18 \%\right)$, pain relief during maximum handgrip strength tests $\left(\mathrm{I}^{2}=0 \%\right)$ and increase in maximum handgrip strength $\left(\mathrm{I}^{2}=0 \%\right)$ in treatment groups effects were mostly homogeneous. Only overall pain relief in control groups $\left(\mathrm{I}^{2}=65 \%\right)$ showed great heterogeneity and pain relief during maximum handgrip strength tests $\left(\mathrm{I}^{2}=33 \%\right)$ showed medium to low heterogeneity. Thus contributing to rather large heterogeneity in the end of treatment comparisons of overall pain $\left(\mathrm{I}^{2}=\right.$ $78 \%)$ and pain during maximum handgrip strength tests $\left(\mathrm{I}^{2}=79 \%\right)$.

\section{Additional files} Additional file 1: Overall pain reduction for physical therapy
groups. (PDF $332 \mathrm{~kb}$ )

Additional file 2: Overall pain reduction in ECSWT groups. (PDF $267 \mathrm{~kb}$ ) Additional file 3: Pain reduction in Non-ECSWT groups. (PDF 274 kb) Additional file 4: Pain during grip strength test relief in LLLT groups. (PDF $240 \mathrm{~kb}$ )

Additional file 5: Pain during maximum grip strength test relief in LLLT-sham groups. (PDF $243 \mathrm{~kb}$ )

Additional file 6: Pain during maximum handgrip strength test reduction in LLLT groups. (PDF $245 \mathrm{~kb}$ )

Additional file 7: Maximum grip strength gain in treatment groups (LLLT and ECSWT). (PDF $233 \mathrm{~kb}$ )

Additional file 8: Maximum grip strength gain in sham-groups (associated with LLLT and ECSWT). (PDF $231 \mathrm{~kb}$ ) 
Additional file 9: Differences between treatment and sham-groups in maximum handgrip strength at the end of treatment (LLLT and ECSWT). (PDF $235 \mathrm{~kb}$ )

\begin{abstract}
Abbreviations
$\mathrm{Cl}$ : Confidence interval; DASH: Disabilities of the arm, shoulder and hand function score; ECSWT: Extracorporeal shockwave therapy; Kg: Kilogram; LE: Lateral epicondylitis; LLLT: Low level laser therapy; LoE: Level of evidence; MD: Mean difference; MVC: Maximum voluntary contraction; MME: Maximum muscle elongation; NSAID: Non-steroidal anti-inflammatory drugs; PEMF: Pulsed electromagnetic field therapy; PET: Problem elicitation technique; PRFEQ: Patient-related forearm evaluation questionnaire; RCT: Randomized controlled trial; SF36: Short form 36 health survey; SIGN: Scottish Intercollegiate Guidelines Network; VAS: Visual analogue scale; WLC: Waiting-list control group; WHO: World health organization.
\end{abstract}

\section{Competing interests}

The authors declare that they have no competing interests.

\section{Authors' contributions}

$C W$ and $V L$ designed the study; $C W, K N, K G$ and $V L$ analyzed the data; $V L, K N$, KG and OC collected data; CW and VL wrote the first draft of the paper; KN, KG, OC contributed to the writing of the paper; CW contributed to analysis and interpretation of the data; CW and KN contributed to the discussions on the design and interpretation of the study. CW and OC conducted final revisions. All authors read and approved the final manuscript.

\section{Acknowledgements}

All authors read and met the ICMJE criteria for authorship and agree with the results and conclusions. None of the authors have received reimbursements, fees, funding or salary from an organization that may in any way gain or lose financially from the publication of this manuscript. None of the authors hold stocks or shares in an organization that may in any way gain or lose financially from the publication of this manuscript.

\section{Author details}

${ }^{1}$ Department of Psychology, TU Darmstadt, Alexanderstrasse 10, 64287 Darmstadt, Germany. ${ }^{2}$ DMB Die MPU Berater GmbH, Bad Nauheimerstrasse 4,

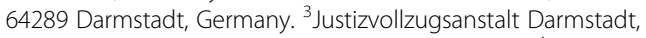
Marienburgstrasse 74, 64297 Darmstadt, Germany. ${ }^{4}$ School of Applied Psychology, University of Applied Sciences and Arts NortherwesternSwitzerland, Riggenbachstrasse 16, 4600 Olten, Switzerland.

\section{Received: 24 July 2013 Accepted: 10 August 2015}

\section{Published online: 25 August 2015}

\section{References}

1. Shiri R, Viikari-Juntura E, Varonen H, Heliövaara M. Prevalence and determinants of lateral and medial epicondylitis: a population study. Am J Epidemiol. 2006;164:1065-74.

2. Buchbinder R, Green S, Struijs P. Musculoskeletal disorders: tennis elbow. Clin Evid. 2008;05:1117-37.

3. NGC-8513. Work Loss Data Institute. Elbow (acute \& chronic). Encinitas (CA): Work Loss Data Institute; 2011

4. Rabago D, Best TM, Zgierska AE, Zeisig E, Ryan N, Crane D. A systematic review of four injection therapies for lateral epicondylosis: prolotherapy, polidocanol, whole blood and platelet-rich plasma. Br J Sports Med. 2009:43:471-81.

5. Krogh TP, Fredberg U, Stengaard-Pedersen K, Christensen R, Jensen P, Ellingsen T. Treatment of lateral epicondylitis with platelet-rich plasma, glucocorticoid, or saline: a randomized, double-blind, placebo-controlled trial. Am J Sports Med. 2013;41(3):625-35.

6. Shiple BJ. How effective are injection treatments for lateral epicondylitis? Clin J Sport Med. 2013;23(6):502-3.

7. Bjordal JM, Lopes-Martins RAB, Joensen J, Couppe C, Ljunggren AE, Stergioulas A, et al. A systematic review with procedural assessments and meta-analysis of Low Level Laser Therapy in lateral elbow tendinopathy (tennis elbow). BMC Musculoskelet Disord. 2008;9:75.
8. Ho LOL, Kwong WL, Cheing GLY. Effectiveness of microcurrent therapy in the management of lateral epicondylitis: a pilot study. Hong Kong Physiother J. 2007;25:14-20

9. Martinez-Silvestrini JA, Newcomer KL, Gay RE, Schaefer MP, Kortebein P, Arendt KW. Chronic lateral epicondylitis: comparative effectiveness of a home exercise program including stretching alone versus stretching supplemented with eccentric or concentric strengthening. J Hand Ther. 2005:18:411-20.

10. Peterson M, Butler S, Eriksson M, Svärdsudd K. A randomized controlled trial of exercise versus wait-list in chronic tennis elbow (lateral epicondylosis). Ups J Med Sci. 2011;116:269-79.

11. Basford JR, Sheffield CG, Cieslak KR. Laser therapy: a randomized, controlled trial of the effects of low intensity Nd: YAG laser irradiation on lateral epicondylitis. Arch Phys Med Rehabil. 2000;81:1504-10.

12. Bisset $L M$, Coppieters MW, Vicenzino B. Sensorimotor deficits remain despite resolution of symptoms using conservative treatment in patients with tennis elbow: a randomized controlled trial. Arch Phys Med Rehabil. 2009;90:1-8.

13. Haake M, Böddeker IR, Decker T, Buch M, Vogel M, Labek G, et al. Sideeffects of extracorporeal shock wave therapy (ESWT) in the treatment of tennis elbow. Arch Orthop Trauma Surg. 2002;122:222-8.

14. Lam LKY, Cheing GLY. Effects of $904 \mathrm{~nm}$ low-level laser therapy in the management of lateral epicondylitis: a randomised controlled trial. Photomed Laser Surg. 2007;25:65-71.

15. Nourbakhsh MR, Fearon FJ. An alternative approach to treating lateral epicondylitis. A randomized, placebo-controlled, double-blinded study. Clin Rehabil. 2008:22:601-9.

16. Pettrone FA, McCall BR. Extracorporeal shock wave therapy without local anesthesia for chronic lateral epicondylitis. J Bone Joint Surg. 2005;87:1297-304.

17. Rompe JD, Hopf C, Küllmer K, Heine J, Bürger R. Low-energy extracorporeal shock wave therapy for persistent tennis elbow. J Bone Joint Surg. 1996;78:233-7.

18. Rompe JD, Riedel C, Betz U, Fink C. Chronic lateral epicondylitis of the elbow: a prospective study of low-energy shockwave therapy and lowenergy shockwave therapy plus manual therapy of the cervical spine. Arch Phys Med Rehabil. 2001;82:578-82.

19. Rompe JD, Decking J, Schoelnner C, Theis C. Repetitive low-energy shock wave treatment for chronic lateral epicondylitis in tennis players. Am J Sports Med. 2004;32:734-43.

20. Speed CA, Nichols D, Richards C, Humphreys H, Wies JT, Burnet S, et al. Extracorporeal shock wave therapy for chronic lateral epicondylitis - a double blind randomised controlled trial. J Orthop Res. 2002;20:895-8.

21. Staples MP, Forbes A, Ptasznik R, Gordon J, Buchbinder R. A randomized controlled trial of extracorporeal shock wave therapy for lateral epicondylitis (Tennis Elbow). J Rheumatol. 2008;35:2038-46.

22. Sterigioulas A. Effects of low-level laser and plyometric exercises in the treatment of lateral epicondylitis. Photomed Laser Surg. 2007;25:205-13.

23. Uzunca K, Birtane M, Tastekin N. Effectiveness of pulsed electromagnetic field therapy in lateral epicondylitis. Clin Rheumatol. 2007;26:69-74.

24. Wolf JM, Mountcastle S, Burks R, Sturdivant RX, Owens BD. Epidermiology of lateral and medial epicondylitis in a military population. Mil Med. 2010;175(5):336-9.

25. Chung B, Wiley JP. Effectiveness of extracorporeal shock wave therapy in the treatment of previously untreated lateral epicondylitis. Am J Sports Med. 2004:32:1660-7.

26. Crowther MAA, Bannister GC, Huma H, Rooker GD. A prospective, randomized study to compare extracorporeal shock-wave therapy and injection of steroid for the treatment of tennis elbow. J Bone Joint Surg. 2002;84-B(5):678-9

27. Mehra A, Zaman T, Jenkin AIR. The use of a mobile lithotripter in the treatment of tennis elbow and plantar fasciitis. Surgeon. 2003;1(5):290-2.

28. Levitt RL, Selesnick H, Ogden J. Shockwave therapy for chronic lateral epicondylitis - an FDA study, Paper presented at: AOSSM Specialty Day, AAOS Annual Meeting. San Francisco: Calif; 2004

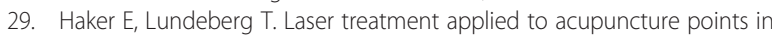
lateral humeral epicondylalgia. A double-blind study. Pain. 1990:43:243-7.

30. Haker E, Lundeberg T. Lateral epicondylalgia: report of noneffective midlaser treatment. Arch Phys Med Rehabil. 1991;72:984-8.

31. Krasheninnikoff M, Ellitsgaard N, Rogvi-Hansen B, Zeuthen A, Harder K, Larsen $\mathrm{R}$, et al. No effect of low power laser in lateral epicondylitis. Scand J Rheumatol. 1994;23:260-3. 
32. Lundeberg $\mathrm{T}$, Haker $\mathrm{E}$, Thomas M. Effect of laser versus placebo in tennis elbow. Scand J Rehab Med. 1987;19:135-8.

33. Pallay RM, Seger W, Adler JL, Ettlinger RE, Quaidoo EA, Lipetz R, et al. Etoricoxib reduced pain and disability and improved quality of life in patients with chronic low back pain: a three month, randomized, controlled trial. Scand J Rheumatol. 2004;33:257-66.

34. Papadopoulos ES, Smith RW, Cawley MID, Mani R. Low-level laser therapy does not aid the management of tennis elbow. Clin Rehabil. 1996;10:9-11.

35. Vasseljen O, Høeg N, Kjeldstad B, Johnsson A, Larsen S. Low level laser versus placebo in the treatment of tennis elbow. Scand J Rehab Med. 1992:24:37-42

36. Benedetti F, Mayberg HS, Wagner TD, Stohler CS, Zubieta J-K. Neurobiological mechanisms of the placebo-effect. J Neurosci. 2005;25:10390-402.

37. Farrar JT, Young Jr JP, LaMoreaux L, Werth JL, Poole RM. Clinical importance of changes in chronic pain intensity measured on an 11-point numerical pain rating scale. Pain. 2001;94:149-58.

38. Altman RD, Zinsenheim JR, Temple AR, Schweinle JR. Three-month efficacy and safety of acetaminophen extended-release for osteoarthritis pain of the hip or knee: a randomized, double-blind, placebo-controlled study. Osteoarthitis Cartilage. 2007;15:454-61.

39. Babul ND, Novek R, Chipman H, Roth SH, Gana T, Albert K. Efficacy and safety of extended-release, once-daily trmadol in chronic pain: a randomized 12-Week clinical trial in osteoarthritis of the knee. J Pain Symptom Manage. 2004;28(1):59-71.

40. Gana TJ, Pascual ML, Fleming RR, Schein JR, Janagap CC, Xiang J. Extendedrelease tramadol in the treatment of osteoarthritis: a multicenter, randomized, double-blind, placebo-controlled clinical trial. Curr Med Res Opin. 2006;22(7):1391-401.

41. Gibofsky A, Williams GW, McMenna F, Fort JG. Comparing the efficacy of cyclooxygenase 2-specific inhibitors in treating osteoarthritis. Arthritis Rheum. 2003;48(11):3102-11.

42. Grifka JK, Zacher J, Brown JP, Seriolo B, Lee A, Moorem A, et al. Efficacy and tolerability of lumiracoxib versus placebo in patients with osteoarthritis of the hand. Clin Exp Rheumatol. 2004;22:589-96.

43. Leung AT, Malmstrom K, Gallacher AE, Sarembock B, Poor G, Beaulieu A, et al. Efficacy and tolerability profile of etoricoxib in patients with osteoarthritis: a 13-week randomized, double-blind, placebo and activecomparator controlled 12-week efficacy trial. Curr Med Res Opin. 2002;18(2):49-58

44. Schnitzer TJ, Gray WL, Paster RZ, Kamin M. Efficacy of tramadol in treatment of chronic low back pain. J Rheumatol. 2000;27:772-8.

45. Simon LS, Weaver AL, Graham DY, Kivitz AJ, Lipsky PE, Hubbard RC, et al. Anti-inflammatory and upper gastrointestinal effects of celecoxib in rheumatoid arthritis. JAMA. 1999;282(20):1921-8.

46. Tannenbaum H, Berenbaum F, Reginster JY, Zacher J, Robinson J, Poor G, et al. Lumiracoxib is effective in the treatment of osteoarthitis oft the knee: a 13 week, randomized, double blind study versus placebo and celecoxib osteoarthritis-pain-intensity-scale. Ann Rheum Dis. 2004;63:1419-26.

47. Öken Ö, Kahraman Y, Ayhan F, Canpolat S, Yorgancioglu ZR. The short-term efficacy of laser, brace, and ultrasound treatment in lateral epicondylitis: a prospective, randomized. Controlled Trial J Hand Ther. 2008;21:63-7.

\section{Submit your next manuscript to BioMed Central and take full advantage of:}

- Convenient online submission

- Thorough peer review

- No space constraints or color figure charges

- Immediate publication on acceptance

- Inclusion in PubMed, CAS, Scopus and Google Scholar

- Research which is freely available for redistribution 